\title{
UMA ABORDAGEM INTEGRADA DE GESTÃO DE RISCOS CORPORATIVOS
}

\section{RESENHA}

MATSUMOTO, André Rodrigues ${ }^{1}$

MATSUMOTO, André Rodrigues. Uma abordagem integrada de gestão de riscos corporativos. Revista Científica Multidisciplinar Núcleo do Conhecimento. Ano 05, Ed. 08, Vol. 14, pp. 83-90. Agosto de 2020. ISSN: 2448-0959, Link de acesso: https://www.nucleodoconhecimento.com.br/administracao/riscos-

\section{corporativos}

\section{RESUMO}

A Gestão de Riscos corporativos é tema central nas organizações que demandam processos organizados e integrados, baseados em análise de riscos. A suplantação das dificuldades que permeiam a implantação de um sistema eficaz, contribui para a busca de um diagnóstico eficaz. Portanto, esse trabalho, tem o objetivo de apresentar uma discussão acerca das partes 1, 2 e 3 do livro "Gestão de Riscos Corporativos: Como integrar a gestão dos riscos com a estratégia, a governança e o controle interno?", escrito por César Ramos (2018), a fim de esclarecer pontos necessários para a construção de um modelo eficiente de Gestão de Riscos.

${ }^{1}$ Mestrando em Administração de Empresas na Universidad Autónoma de Asunción UAA. Asunción - Paraguay. MBA em Finanças Corporativas pela Universidade Veiga de Almeida, UVA/RJ, Brasil. Especialização em Consultoria Econômica pela Universidade Estadual do Oeste do Paraná, UNIOESTE, Brasil. Graduação em Ciências Econômicas pela Universidade Estadual do Oeste do Paraná, UNIOESTE, Brasil. 
Palavras-Chave: Gestão de riscos corporativos, estratégia, governança, controle interno.

\section{INTRODUÇÃO}

Detentor de vasta experiência em auditoria e consultoria, César Ramos apresentanos em sua obra intitulada "Gestão de Riscos Corporativos: Como integrar a gestão dos riscos com a estratégia, a governança e o controle interno?", uma gama de análises, capaz de introduzir o mais leigo leitor, nesse interessante universo do gerenciamento de riscos. O presente trabalho, não tem o intuito de tratar exaustivamente cada uma das três partes do seu livro, apenas tem a missão de ressaltar aspectos elementares e relevantes. Possui o desafio de trazer para o leitor a noção de um enfoque mais integrado de gestão de risco corporativo. Assim, são expostos elementos que abordem de forma mais estratégica a mitigação de risco e a agregação de valor aos acionistas, corroborando a forte integração que deve haver entre a Gestão de Riscos, a estratégia, a governança e o controle interno.

\section{DESENVOLVIMENTO}

A parte 1 vem inaugurar algumas questões e conceitos importantes para o bom entendimento do assunto. Inicialmente, o autor define o risco, como uma probabilidade de perigo, ou mais, sucintamente, como uma incerteza, que podem ser matematizadas ou não. Em dado momento, defende que analisar risco, pode equivaler à prática da futurologia; arte concebida para prever ameaças, riscos e oportunidades. Ao mesmo tempo, incita-nos a se preocupar com o processo da globalização, um fenômeno que tem acirrado cada vez mais a concorrência entre as organizações. Sejam problemas econômicos, financeiros ou ambientais, os efeitos adversos repercutem em escala global, atingindo diversos países, produzindo os mais diversos reflexos negativos. Para César Ramos, a incerteza é algo prevalecente, na medida em que induzem as empresas a verificar periodicamente suas visões de futuro e de ambiente, a fim de se compatibilizar ao meio em que estão inseridas. Para suplantar as incertezas, é essencial que a análise de risco esteja atrelada ao planejamento estratégico. 
Ramos (2018), baseado no relatório 2018 de riscos globais ("The global Risks Report 2018, 13th Edition"), chama a atenção para os Riscos Globais, que tem crescido num ritmo acelerado, com iminência de já representar riscos para as pessoas e para as organizações. Destaca que os riscos globais são abertamente interconectados, com forte tendência de afetar outros diversos riscos. A crescente urbanização, a degradação ambiental, variações climáticas, o envelhecimento populacional, a dependência com tecnologias de informação e o avanço das desigualdades econômicas e sociais são fruto desse contexto.

Ainda, o autor traz-nos outra definição de risco, oriunda da ISO 31000, segundo o qual, o risco deve ser entendido, como uma incerteza ligado a uma ocorrência de um desvio de um resultado esperado para a consecução do objetivo. Corrobora também que um risco tem geralmente três componentes, quais sejam: As causas de realização do risco, a probabilidade de sua ocorrência e a magnitude das consequências do risco, em termos financeiros e operacionais. Ao se deparar com uma organização, o risco corporativo pode ser observado como a dispersão de resultados de uma instituição num dado período de tempo, devido à alteração em outras variáveis importantes. Nesse caso, a incerteza é produto da magnitude dessa dispersão.

Conectando-se com esse pensamento, Cocurullo (2003), conceitua o risco, como algo que é capaz de impedir o atingimento dos objetivos corporativos, ou mesmo a ausência de situações necessárias para alcançar os referidos objetivos. Sua concepção é pautada na visão de que o risco não deve ser limitado apenas ao campo financeiro, visto, que uma instituição também compreende em seu arcabouço diversos objetivos em suas mais diversas áreas.

Durante a obra de Ramos (2018), é nos apresentado a tipificação dos riscos corporativos, revelando-nos que de certa forma é possível classificá-los de diversas formas. No entanto, pode-se dividir os riscos corporativos basicamente em três principais categorias: riscos de ambiente econômico, político e legal, riscos operacionais e riscos ligados às informações, utilizadas para tomada de decisões. 
$\mathrm{Na}$ análise de Ramos (2018), é imprescindível que um sistema de gestão de riscos corporativos possibilite à entidade extrair dados sobre seus riscos, bem como sobre suas exposições.

Para que haja êxito na construção do sistema de gestão de riscos, é primordial que os objetivos da organização estejam adequadamente documentados, para que seja possível a identificação dos eventos que impediriam sua realização. De posse desse desenho, a entidade tem a garantia de dispor de um processo eficaz e coadunado com a estratégia, sendo compatíveis com o apetite a riscos, além de possibilitar o gerenciamento da incerteza.

Essa configuração, pode ser observada com Moraes (2010), o qual defende que o gerenciamento de riscos deve conter em seu bojo, práticas, processos e métodos de trabalho de toda a corporação, permitindo assim, obter uma operação segura, eficiente e eficaz. Como parte de sua compreensão, a gestão de riscos, deve estar integrada a todos os processos organizacionais.

Algo paradigmático desencadeado na obra, refere-se a outros três itens, além da gestão de riscos, que comumente são abordados separadamente na literatura: a estratégia, o controle interno e a governança corporativa. Todos são tratados de forma muito especializada, sem uma noção de pensamento integrado. Essas peças, muitas vezes são apresentadas à alta administração de modo muito específico, sendo jamais exposto de forma global. César Ramos, defende que a integração deles é realmente uma necessidade lógica e inteligente de todo esse processo. Cada qual com seu papel de relevância deve contribuir para o funcionamento eficiente da estrutura. A estratégia, através de planos e metas leva os negócios da corporação na direção desejada, dado o apetite de risco que tem. Cabe à governança apresentar as políticas e normas que devem ser aplicadas na entidade. E o controle interno, tem a grande tarefa de mapear, analisar e reconstruir processos e controles de forma adequada e eficaz.

A gestão de riscos enquanto processo, requer desenvolvimento contínuo, sendo necessário também o monitoramento permanente por parte da alta gestão. No mínimo 5 etapas, faz-se essencial para a boa concretização do sistema: processo de 
identificação de riscos, processo de avaliação de riscos, processo de construção dos planos de tratamento, processo de implementação dos planos e o processo de monitoramento contínuo dos riscos.

Deve-se compreender que a gestão de riscos é um processo cíclico e de ações, na qual cada ciclo denunciará os pontos de melhoria que serão incluídos no sistema. $O$ autor então reafirma o papel relevante que a alta administração detém nesse contexto, dada sua responsabilidade para condução do processo. Pode-se reforçar esse raciocínio com Baraldi (2005), o qual tem-se que, "O gerenciamento de riscos empresariais são os conhecimentos, os métodos e os processos organizados para reduzir os prejuízos e aumentar os benefícios na concretização dos objetivos estratégicos". E mais além, Assi (2012), entende que a intensidade desse processo, extrapola a identificação, avaliação e administração de riscos, no cenário de incertezas, pois é capaz de contribuir para integração do processo de criação e preservação de valor.

Ainda com Nohara et al. (2005), propõe-se que o Gerenciamento de Risco Corporativo, deve assumir a configuração de um sistema. Compreende-se que dada a existência de diversas atividades numa entidade, torna-se necessário a reunião disso tudo em um conjunto de informações. Considera que os riscos não devem ser analisados isoladamente pelos departamentos, sendo necessário desenhá-lo de forma que assuma um fluxo integrado.

Na parte 2, Ramos (2018), segundo sua visão, exibi-nos os melhores sistemas de gestão de riscos, identificando as melhores práticas, bem como características teóricas e lógicas dos sistemas.

Os 5 sistemas abordados, apresentam semelhanças na sua estrutura lógica, sendo o que destoa entre um e outro é sua organização. Todos, representam uma ótima alternativa para customização e obtenção da integração tão desejada para uma corporação. 
O primeiro modelo considerado, a Marina Americana, é muito simples e objetivo, capaz de abranger os principais pontos necessários para um sistema de gestão de riscos adequado. Os controles são baseados principalmente na replicação educacional, ou seja, são baseados em treinamentos e preparação das tropas para a missão com instruções simples e bem esclarecidas.

O processo de gestão de riscos da NASA, contém uma particularidade voltada para o meio empresarial, na medida em que a gestão de riscos é focada em cada programa da NASA. Outro ponto de destaque, é que esse modelo é aplicado sucessivamente em todos os níveis da corporação. Além disso, cada unidade de operação é responsável pela gestão de seus próprios riscos e também dos riscos da unidade subordinada a ela.

O modelo COSO ERM 2004, apresenta-se como uma boa escolha para organizações que desejam a implementação de um sistema de gestão de riscos. Baseia-se na criação de uma estrutura de controle interno que tem como intuito cumprir as metas de desempenho e lucro, bem como evitar perdas financeiras. A sua política de gestão de riscos pauta-se em quatro principais objetivos: Objetivos estratégicos, Objetivos Operacionais, Objetivos de comunicação e Objetivos de conformidade. No entanto, todos os objetivos devem ser constituídos a nível estratégico, servindo de base para os demais, e alinhados com o apetite ao risco.

Ramos (2018) esclarece que a nova versão do modelo COSO, de 2017, vem modificar a visualização dos riscos a nível de estratégia. Não cabe apenas avaliar todos os riscos que impactam nas estratégias da organização, deve-se observar também se as estratégias estão de acordo com os objetivos e metas da entidade. Isso significa de certa forma, que há possibilidade das estratégias não estarem coadunadas com os objetivos e metas da instituição. As características evidenciadas do modelo demonstram que essa estrutura fornece bases fortes para que haja a integração da gestão de riscos com a estratégia, a governança e os controles internos.

Para ISO 31000, o autor esclarece, que representa uma norma com o fim de expor os princípios e as diretrizes que uma corporação deverá seguir para ter um sistema de 
gestão de riscos eficaz. O risco aqui, é definido como um componente de incerteza e a gestão de riscos como atividades coordenadas que tem o intuito de dirigir e controlar uma entidade segundo seus riscos.

O autor aponta as semelhanças contidas entre os sistemas de gestão de riscos, sendo notado que algumas diferenças são mais percebidas a nível de organização. Todos os sistemas discutidos são candidatos a uma implantação, podendo se constituir em um eficaz sistema integrado de gerenciamento de riscos.

A terceira e última parte, é dedicada a trazer um modelo abrangente de Gestão de Riscos Corporativos. Alinhado a questões regulatórias, como a Lei anticorrupção ou a Lei Sarbanes-Oxley. O intuito é apresentar um modelo que ajude os gestores de riscos. Como mencionado anteriormente, a gestão de riscos, o controle interno e a governança, comumente são abordados de forma separada. A proposta do autor foi demonstrar um modelo em que esses vértices estivessem integrados.

Inicialmente, ele, afirma, que seja qual for o sistema de gestão de riscos corporativos, é imprescindível que a organização documente os objetivos e metas de acordo com o plano estratégico. Essa definição é primordial para estabelecer a base para os objetivos operacionais, de comunicação e de cumprimento de normas. Outrossim, esse delineamento deve estar alinhado com o apetite ao risco, demarcando os riscos máximos a serem assumidos pela entidade.

Para a consecução do modelo idealizado, o autor, propõem a execução de 11 atividades, que seriam: Diagnóstico da situação inicial; Definição dos objetivos e metas da administração; Desenho da estrutura de gestão de riscos; Identificação e mapeamento dos riscos; Mapeamento e avaliação dos processos e controles; Definição dos planos de tratamento dos riscos; Implementação dos planos de tratamento dos riscos; Adaptação das atividades de supervisão e controle; Adaptação dos reportes financeiros e gerenciais; Adaptação das regras de monitoramento do processo de gestão de riscos e Implementação de mudanças e melhorias. 
O modelo de gestão de riscos corporativos proposto por César Ramos apresenta em seu desenvolvimento traços da estrutura da norma ISO 31000, abrangendo componentes do COSO, bem como da estrutura de gestão de riscos presentes na norma ISO 31000. Organizadamente, atividades inerentes a cada um dos dois são coincidentes em cada uma das 11 atividades oferecidas, diferindo em um ou outro ponto. Dessa forma, Estratégia, Governança e Controle Interno estarão contidos entre uma etapa e outra.

\section{CONSIDERAÇÕES FINAIS}

Dados os aspectos mencionados, é pertinente depreender a partir da obra, que o gerenciamento de riscos corporativos possui forte relação com a estratégia, a governança e o controle interno. Comumente como citado, esses quatro elementos são debatidos na literatura de forma muito específica, sendo tratados cada qual de forma isolada, sem muita correlação entre um e outro. Pressupõem-se que para o bom desenvolvimento do gerenciamento de riscos corporativos, faz-se necessário considerar a adoção de um sistema de gestão de riscos coeso. E diante de um conjunto de modelos disponíveis, cabe à organização definir o que melhor se adéqua. Considerar a escolha seja qual for o sistema, também denota total atenção para que se documente principalmente os objetivos e metas de acordo com a estratégia da organização. É com base nesses pilares que se tem o alinhamento com o apetite ao risco que a entidade deseja essencialmente assumir. Sabiamente, o autor nos surpreende com a sugestão de um sistema de gerenciamento de riscos corporativos, fruto da inspiração caucada na diversidade de modelos já existentes. A premissa que envolve a sua construção de modelo de gestão de riscos é norteada pela integração com a estratégia, o controle interno e a governança corporativa, algo realmente necessário. Infere-se que a eficácia de um modelo de gerenciamento de riscos corporativos está atrelada à integralização desses atores, sem a qual, torna-se pouco factível a agregação de valor à organização. 


\section{REFERÊNCIAS}

ASSI, Marcos. Gestão de riscos com controles internos: ferramentas, certificações e métodos para garantir a eficiência dos negócios. São Paulo: Saint Paul Editora, 2012.

BARALDI, Paulo. Gerenciamento de riscos empresariais: a gestão de oportunidades, a avaliação de riscos e a criação de controles internos nas decisões empresariais. 2. Ed. Rio de Janeiro: Elsevier, 2005.

COCURULLO, Antônio. Gestão de riscos corporativos: riscos alinhados com algumas ferramentas de gestão: um estudo de caso no setor de celulose e papel. São Paulo: Scortecci, 2002.

MORAES, Giovani. Sistema de Gestão de Riscos - Princípios e Diretrizes - ISSO 31000/2009 Comentada e Ilustrada. Rio de Janeiro: Gerenciamento Verde Consultoria, Editora e Livraria Virtual, 2010.

NOHARA, J. J.; ACEVEDO, C. R.; VILA, A. R. Aplicação da Gestão do Conhecimento em Processos de Gerenciamento de Risco. In: Encontro Nacional de Engenharia de Produção, XXV. Porto Alegre, 2005, p. 2641-2648.

RAMOS, César. Gestão de Riscos Corporativos: Como integrar a gestão dos riscos com a estratégia, a governança e o controle interno? São Paulo: CR Editora, 2018.

Enviado: Dezembro, 2019.

Aprovado: Agosto, 2020. 